\title{
A importância da Feira Estadual de Ciências para a Divulgação Científica em Roraima
}

\section{The importance of the State science fair for scientific dissemination in Roraima}

\author{
Esterline Félix dos Reis (felix.ester@hotmail.com)
}

Mestranda no Programa de Mestrado Profissional em Ensino de Ciências da Universidade Estadual de Roraima (UERR).

\author{
Alcinda de Souza Muniz Teixeira (alsomuniz@hotmail.com) \\ Mestranda no Programa de Mestrado Profissional em Ensino de Ciências da \\ Universidade Estadual de Roraima (UERR).
}

Bianca Maíra de Paiva Ottoni Boldrini (biancaottoni@gmail.com)

Doutora em Ciências Biológicas Entomologia pelo Instituto Nacional de Pesquisas da Amazônia (INPA).

Professora do Programa de Mestrado Profissional em Ensino de Ciências da Universidade Estadual de Roraima (UERR).

Ivanise Maria Rizzatti (niserizzatti@gmail.com)

Doutorado em Química pela Universidade Federal de Santa Catarina (UFSC). Professora no Programa de Mestrado Profissional em Ensino de Ciências da Universidade Estadual de Roraima (UERR).

Resumo: Este artigo é resultado de uma pesquisa realizada durante o curso no Programa de Pós-Graduação em Ensino de Ciências da Universidade Estadual de Roraima, e teve como objetivo avaliar a contribuição da Feira Estadual de Ciências de Roraima - FECIRR, para a Divulgação Científica em Roraima, segundo a concepção de professores dos anos finais do ensino fundamental, participantes da FECIRR. A metodologia consistiu de uma pesquisa de campo do tipo qualitativa, onde aplicou-se um questionário contendo cinco questões a dez professores durante a XXVI FECIRR, ocorrida em novembro de 2018 no Parque Anauá, situado na capital Boa Vista. Buscouse com isso, informações sobre o envolvimento de alunos e professores na Feira de Ciências e a relação do processo como um todo para o desenvolvimento de habilidades como as presentes no novo documento normativo, a Base Nacional Comum Curricular - BNCC. Os resultados demonstraram que as Feiras de Ciências contribuem significativamente para a Divulgação Científica em Roraima. Assim, é necessário incentivar a popularização de eventos como esses para colaborar no processo de ensino e aprendizagem dos alunos, bem como, permitir que a comunidade tenha acesso às informações científicas levantadas.

Palavras-chave: Feira de Ciências; Ensino de Ciências; Aprendizagem.

Abstract: This article is the result of research carried out during the course in the Graduate Program in Science Teaching at the State University of Roraima, and aimed to evaluate the contribution of the State Science Fair of Roraima - FECIRR, to the 
Scientific Dissemination in Roraima, according to the conception of teachers from the final years of elementary school, participating in FECIRR. The methodology consisted of a qualitative field research, where a questionnaire was applied containing five questions to ten teachers during the XXVI FECIRR, which took place in November 2018 in Parque Anauá, located in the capital Boa Vista. This sought information about the involvement of students and teachers in the Science Fair and the relationship of the process as a whole to the development of skills such as those present in the new normative document, the National Common Curricular Base - BNCC. The results showed that the Science Fairs contribute significantly to Scientific Dissemination in Roraima. Thus, it is necessary to encourage the popularization of events like these to collaborate in the teaching and learning process of students, as well as, allowing the community to have access to the scientific information raised.

Keywords: Science Fair; Science teaching; Learning.

\section{INTRODUÇÃO}

Nos últimos tempos, tem-se percebido um distanciamento entre a Ciência e a população. Neste sentido, universidades, pesquisadores e cientistas cada vez mais reúnem esforços para minimizar os efeitos desse distanciamento, tendo a Divulgação Científica (DC) como possibilidade para se aproximar da sociedade. A DC permite que pesquisas e trabalhos de origem científica e/ou tecnológica possam ser acessados e compreendidos pela população em geral, podendo acontecer por diferentes meios, tais como, traduções, ilustrações, recursos visuais, eventos, feiras, entre outros (FRANÇA, 2015).

Assim, a DC visa despertar o interesse da população pela Ciência e Tecnologia, mostrando como ela está presente na vida das pessoas, apresentando seus benefícios para a melhoria da qualidade de vida ou prejuízos à vida terrestre. Para tanto, é necessário que o cidadão seja alfabetizado científica e tecnologicamente, de forma a promover a democratização da ciência por meio da DC. E quanto mais cedo esse processo for iniciado, mais fácil a aproximação entre os produtores e os consumidores da ciência e da tecnologia.

Nessa direção, as Feiras de Ciências podem contribuir para o processo de alfabetização científica e tecnológica, uma vez que são entendidas, segundo Silva, Almeida e Lima (2018), como locais públicos onde alunos, por meio de uma atividade científica investigativa, expõem o resultado de suas descobertas para a comunidade. Considerando a importância das feiras de Ciências, em especial, a Feira Estadual de Ciências de Roraima - FECIRR, este artigo tem como objetivo avaliar a contribuição da 


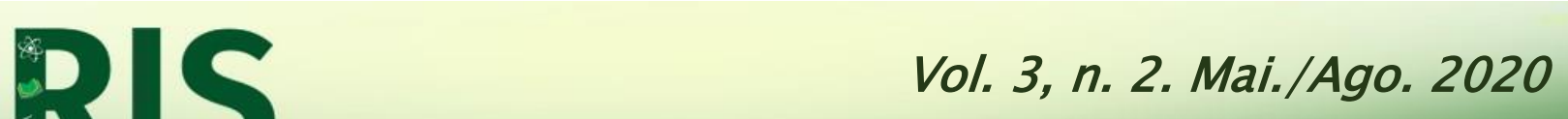

ISSN: 2595- 4520

XXVI FECIRR para a Divulgação Científica no estado, segundo a concepção de professores dos anos finais do ensino fundamental, participantes da feira. A pesquisa foi realizada durante a disciplina de Divulgação Científica e o Ensino de Ciências, componente curricular do Mestrado Profissional em Ensino de Ciências da Universidade Estadual de Roraima (UERR).

O tema é relevante, pois muitas escolas de Roraima já inseriram a Feira de Ciências em seus calendários escolares, sendo oportuno analisar o entendimento sobre a relação entre esses eventos e a DC no estado.

\section{DIVULGAÇÃO CIENTÍFICA}

A Divulgação Científica (DC) tem como objetivo garantir o acesso da população aos conhecimentos da ciência e da tecnologia, percebendo seus impactos na sociedade e no ambiente. Bueno (2010, p. 5) destaca que a função da DC é a de "democratizar o acesso ao conhecimento científico e estabelecer condições para a chamada alfabetização científica". Considera ainda que a divulgação é um "estágio inicial para chegar à cultura científica satisfatória".

Neste aspecto, entende-se que a DC é uma iniciação a cultura científica, onde o interesse surge através de eventos relacionados a Ciência aguçando o interesse de quem a faz e de quem se beneficia, surgindo assim a Educação Científica, sendo ela o início desse processo. O papel do pesquisador, não pode se limitar aos seus interesses quando divulga seu trabalho, como explica Barros (2005), deve também contribuir para o avanço do conhecimento e melhoria da qualidade de vida, além de atuar, também, como uma prestação de contas à sociedade. Desta forma:

\footnotetext{
O pesquisador sente a necessidade de transformar resultados de seu trabalho em notícia vinculada pelos meios de divulgação (jornais, revistas, televisão, internet), uma vez que essa visibilidade pode facilitar a obtenção de recursos necessários para o desenvolvimento da pesquisa e para o reconhecimento entre os colegas (BARROS, 2005, pág. 111).
}

O movimento da DC no Brasil não é recente e de acordo com Massarani (2005), divulgadora científica, ela se inicia com a chegada da Corte portuguesa ao Brasil em 1808. A autora destaca algumas fases mais importantes da DC no Brasil, a qual se iniciou timidamente a partir de 1810 , onde houve uma preocupação com a DC, tendo 
em vista a presença da Família Real Portuguesa aqui, e um dos pontos mais importantes foi a criação do Jornal “O Patriota” por D. Pedro II (MASSARANI, 2005).

Nesse caso, observa-se que os pesquisadores e cientistas começam a pensar e evidenciar como os benefícios da Ciência poderiam melhorar as condições de vida da população. Para Massarani (2005), a diversidade de informações foi o ponto chave desse pensamento, e enfatiza que muitos temas foram dirigidos à população, tais como: as questões de saneamento básico, campanhas de vacinação, doenças transmissíveis, entre outras.

Para os cientistas a Sociedade Brasileira para o Progresso da Ciência (SBPC) que foi fundada em 1948, foi uma conquista, visto que essa associação é uma entidade sem fins lucrativos que está voltada, principalmente, para o desenvolvimento científico e tecnológico do Brasil. Segundo Duarte (2008) outro fator fundamental para a DC no Brasil foi a Rádio Sociedade do Rio de Janeiro, fundada em abril de 1923, que teria sido a primeira rádio brasileira, a qual foi criada por um conjunto de cientistas, professores e intelectuais, entre eles membros da Academia Brasileira de Ciências (ABC), que se juntaram para implantar o novo veículo de comunicação, que tinha como objetivo a difusão de informações e de temas educacionais, culturais e científicos. Acreditava-se que o rádio permitiria uma transmissão de conhecimentos, fácil, rápida e que atingiria os locais mais distantes do país.

Nesse contexto, merece destaque também a criação do Conselho Nacional de Desenvolvimento Científico e Tecnológico - CNPq, fundado em 1951 e que tem importante papel na área da pesquisa brasileira, especialmente no financiamento de recursos humanos, onde suas atividades incluem auxílio para pesquisadores brasileiros no exterior e para pesquisadores estrangeiros no Brasil. Ou seja, o CNPq é uma agência do Ministério da Ciência, Tecnologia, Inovação e Comunicação (MCTIC) destinada ao fomento da pesquisa científica e tecnológica e à formação de recursos humanos para a pesquisa no país.

Segundo Massarani (2005) os últimos anos têm sido marcados por inúmeras experiências de DC no Brasil, com o objetivo de fortalecer uma visão mais democrática atribuída a estas atividades científicas que incorporem também as ciências sociais; promover uma maior interação entre ciência, cultura e arte, valorizando os aspectos culturais e humanos da ciência; estimular a participação popular no debate sobre os impactos resultantes da Ciência e Tecnologia (C\&T). 
Nesta perspectiva, Valerio (2005) destaca que o fortalecimento e a expansão da DC são comprovados por iniciativas em instituições públicas brasileiras, algumas englobando a Ciência e a DC, tais como as reuniões anuais da Sociedade Brasileira para o Progresso da Ciência (SBPC), e mais a criação de dezenas de centros e museus de ciência, a presença mais constante da ciência na mídia, o estabelecimento de um departamento no Ministério da Ciência e Tecnologia voltado para a popularização e a difusão da C\&T. Neste aspecto, Caldas (2010, p. 33) entende que:

\begin{abstract}
Considerando que quase tudo que acontece na sociedade é influenciado pela $\mathrm{C} \& \mathrm{~T}$, é preciso que o discurso científico seja amplamente compreendido pela população, para que possa tomar suas decisões a partir de múltiplas informações, considerando os aspectos positivos e negativos de cada situação (CALDAS, 2010, p.33).
\end{abstract}

São pontos relevantes para DC no Brasil, onde percebe-se que desde o início aos tempos atuais as experiências na área vêm se diversificando pelo uso de vários instrumentos e canais de DC, como museus e centros de ciência, centros culturais, internet, redes sociais, audiovisual, teatro, livros, revistas e feira de ciências. Como reforça Garroti (2014),

Há diversas formas de divulgar ciência para o público leigo: artes (cinema, teatro, quadrinhos, música, poesia, enfim, diversos canais); jornalismo científico (desde o das grandes mídias, TV, documentários, até o das regionais/locais, passando pelos meios eletrônicos e digitais, como blogs de ciência); palestras, cursos variados, redes sociais, dentre muitos outros formatos (GARROTI, 2014, p. 35).

Além dessas variadas formas de DC no Brasil, destaca-se a Semana Nacional de Ciências e Tecnologia (SNCT) que é realizada nacionalmente desde 2004, coordenada pelo MCTIC com a colaboração de empresas e órgãos públicos, escolas, fundações de apoio, institutos de pesquisa, museus, secretarias estaduais e universidades. Para o então secretário de Políticas e Programas de Pesquisa e Desenvolvimento do MCTIC, Jailson de Andrade, a SNCT é de suma importância para a divulgação da ciência e tecnologia no país. Ele ainda ressalta que: "A SNCT é extremamente importante para o Brasil, por dar a oportunidade de os jovens brasileiros conhecerem de perto a ciência e tecnologia" (MCTIC, 2017, p. 2).

A $15^{\text {a }}$ edição da SNCT foi realizada de 15 a 21 de outubro de 2018. A inspiração é a Agenda 2030 e seus 17 Objetivos de Desenvolvimento Sustentável (ODS), estabelecidos pela Organização das Nações Unidas (ONU). Onde trouxe o tema "Ciência para a Redução das Desigualdades", um debate acerca da contribuição das 
Ciências Sociais e Humanas para a redução das desigualdades no Brasil. Com intuito de fomentar os usos sociais da ciência e da tecnologia, permitindo ampliar as possibilidades de se combater a desigualdade social por meio da popularização e da divulgação da ciência e da tecnologia. Com isso, contribuir para a disseminação e popularização de soluções de problemas cotidianos que impactam a vida da maioria da população brasileira de suma importância para o desenvolvimento e diminuição da desigualdade do país.

\section{FEIRA DE CIÊNCIAS EM RORAIMA}

As Feiras de Ciências são eventos que permitem ao aluno socializar ideias em projetos juntamente com outros alunos, com o professor orientador e com a comunidade que prestigia as feiras, contribuindo para o seu processo de ensino-aprendizagem, bem como para a popularização da Ciência.

Sendo assim, torna-se oportuno delinear o entendimento que se tem sobre as Feiras de Ciências. Nesse sentido, o Programa Nacional de Apoio as Feiras de Ciências da Educação Básica (FENACEB) do Ministério da Educação pontua que as Feiras de Ciências são:

Eventos sociais, científicos e culturais realizados nas escolas ou na comunidade com a intenção de, durante a apresentação dos estudantes, oportunizar um diálogo com os visitantes, constituindo-se oportunidade de discussão sobre os conhecimentos metodológicos de pesquisa e criatividade dos estudantes em todos os aspectos referentes à exibição dos trabalhos (FENACEB, 2006, p. 20).

Acrescenta-se a este entendimento a perspectiva de Ormastroni (1990) sobre as Feiras de Ciências:

É uma exposição pública de trabalhos científicos e culturais realizados por alunos. Estes efetuam demonstrações, oferecem explicações orais, contestam perguntas sobre os métodos utilizados e suas condições. Há troca de conhecimentos e informações entre alunos e o público visitante (ORMASTRONI, 1990, p. 7).

Para Sousa (2015, p.17) as Feiras de Ciências são consideradas "um instrumento de grande relevância para o processo de ensino aprendizagem de ciências quando realizadas nos espaços não-formais e como atividade extraclasse". Ao colocar em prática as Feiras de Ciências para que os alunos possam executar projetos de acordo 
com um tema geral, permite-se aos alunos o amadurecimento de ideias e conceitos que contribuem para o seu desenvolvimento individual e coletivo.

Assim, entende-se que as Feiras de Ciências tem como objetivo permitir ao aluno praticar a pesquisa científica investigativa pensando de maneira crítica para então, expor o resultado do seu trabalho à comunidade que prestigia o evento, podendo propiciar a este aluno o desenvolvimento de habilidades como criatividade, oralidade, capacidade de resolver problemas, entre outros. Ao mesmo tempo possibilitando à comunidade que o prestigia acesso à informação, contribuindo para a divulgação científica, conforme aponta Borba (1996, p.43),

A feira desenvolve no aluno a ação democrática de participação coletiva. Permite a troca de experiências, libera o aluno para um pensar criativo em que a sua capacidade de comunicação é exercitada. Consequentemente, após atuar em uma feira de ciências, nosso aluno retornará à sala de aula com maior capacidade de decisão em relação aos problemas do nosso cotidiano (BORBA, 1996, p.43).

A presença das Feiras de Ciências nas comunidades escolares se iniciou em 1950 quando ocorreu a primeira Feira Internacional de Ciências na Filadélfia, nos Estados Unidos da América. Na época um grupo de professores incentivou seus alunos a desenvolverem projetos científicos e foram expostos os que mais se destacaram (FENACEB, 2006).

No Brasil, as Feiras de Ciências iniciaram a partir de 1960 por meio do Instituto Brasileiro de Educação, Ciência e Cultura (IBECC), onde professores puderam ser treinados para organizar os Centros de Ciências (GIORGION, 2010). Possibilitando que professores e estudantes pudessem realizar experimentos, utilizar laboratórios, publicar guias para os professores, formar núcleos profissionais para o desenvolvimento do conhecimento científico e que, posteriormente, originaram os centros de Ciências (SOUSA, 2015).

Em Roraima, a primeira Feira Estadual de Ciências aconteceu em 1986 e foi organizada pelo Centro de Ciências de Roraima (CECI-RR). Participaram da exposição 17 escolas de primeiro e segundo graus, bem como, outras instituições. Como resultado percebeu-se a "necessidade de cursos de Iniciação à Educação Científica e cursos Preparatórios para a realização de Feiras de Ciências e de produção científica" (SOUSA, 2015, p.79). 
Segundo aponta Sousa (2015), o CECI-RR organizou e realizou 14 edições da FECI-RR, nos anos de 1986 a 1998, e em 2001. Em 1997 o estado de Roraima sediou pela primeira vez na região norte a Feira Nacional de Ciências do Brasil (IX FENACI), e contou com a participação de 15 estados, 2402 estudantes e 531 professores. Denotando a importância do estado de Roraima no cenário brasileiro em relação às Feiras de Ciências e DC.

A autora acrescenta que, devido a problemas ocasionados pela interrupção de recursos financeiros e humanos não foram realizadas as Feiras Estaduais nos anos de 1999, 2000 e de 2002 a 2005 (SOUSA, 2015). O que resultou em uma lacuna significativa na história das Feiras de Ciências em Roraima impedindo os alunos das escolas do estado de exporem seus trabalhos de pesquisa e, possivelmente, podando a motivação pela pesquisa científica.

Em 2005 ocorreu a extinção do CECI-RR e as Feiras de Ciências ficaram sob a responsabilidade da Secretaria Estadual de Educação de Roraima (SEED). Devido a problemas e dificuldades tanto de pessoal como financeira, as Feiras foram realizadas apenas em 2006, 2007 e 2008. No ano seguinte, a organização da Feira Estadual de Ciências foi atribuída à Universidade Estadual de Roraima sendo vinculada ao Núcleo de Pesquisa em Ensino de Ciências e Matemática (NUPECEM/UERR) e o Centro de Formação dos Profissionais da Educação de Roraima (CEFORR) (SOUSA, 2015).

Em 2009, a feira foi realizada no espaço da UERR, e em 2010 não foi realizada. Contudo, a partir de 2011 as edições da feira foram realizadas normalmente, chegando a sua XXVI edição em 2018. Em 2018 o tema da feira foi “A Ciência para a redução da desigualdade", estando o tema vinculado à Semana Nacional de Ciência e Tecnologia. Paralelamente a FECIRR, ocorre também a Mostra Científica de Química da Amazônia Setentrional e o Torneio Estadual de Robótica Educacional.

Desta forma, entende-se que as Feiras de Ciências são eventos de grande relevância para a educação, pois permite a difusão de conhecimentos científicos gerados nas escolas e universidades, sendo compartilhados com a sociedade.

\section{METODOLOGIA}


A metodologia de estudo é a pesquisa de campo de abordagem qualitativa, tendo como instrumento de coleta de dados a aplicação de questionário contendo cinco questões, sendo duas objetivas e três discursivas. Ao final, foram entrevistados dez professores dos anos finais do ensino fundamental de escolas da rede pública do município de Boa Vista.

A pesquisa foi realizada durante o período da Feira Estadual de Ciências de Roraima - FECIRR, que ocorreu no Parque Anauá, localizado no município de Boa Vista - RR, entre os dias 22 e 24 de novembro de 2018. Os professores entrevistados foram os orientadores dos projetos apresentados durante a feira.

Os professores participantes foram informados que se tratava de um trabalho de pesquisa da disciplina de Divulgação Científica e o Ensino de Ciências, componente curricular do curso de Mestrado Profissional em Ensino de Ciências da UERR, cursada entre os meses de agosto e dezembro de 2018, e que seus nomes seriam mantidos em sigilo. Os questionários foram entregues pessoalmente aos professores durante a FECIRR e a análise dos dados foi feita mediante reflexão sobre as respostas e o que aponta a bibliografia consultada sobre a temática abordada. Os respondentes foram identificados por códigos P1(Professor 1) à P10 (Professor 10).

\section{RESULTADOS E DISCUSSÕES}

Os professores participantes da pesquisa atuam em escolas localizadas em sua maioria na zona leste de Boa Vista. Tendo como formação Pedagogia, Matemática, Língua Portuguesa, História, Ciências, Artes e Religião. O tempo de docência dos professores/orientadores varia entre 10 e 34 anos.

Para a execução da pesquisa os professores responderam ao questionário solicitado previamente onde na primeira questão buscou-se compreender $o$ entendimento dos mesmos sobre as Feiras de Ciências. Cinco professores afirmaram se tratar de um projeto de ensino e pesquisa, quatro afirmaram se tratar de um evento científico e apenas um afirmou se tratar de um espaço de DC.

Esse percentual demonstra que quase metade dos professores veem a Feira de Ciências apenas como um evento e não como um processo que promove a construção do conhecimento, tendo o aluno como ponto central desse processo. A Divulgação 
Científica em espaços como a Feiras de Ciências necessita ser popularizada, para aproximar a comunidade dos conceitos científicos valorizando a Ciência. Como exemplifica Netto (2010) as Feiras de Ciências são eventos que constituem o mais completo processo de DC, além de atuarem na transmissão da cultura científica oportunizando troca de experiências entre os expositores e os visitantes que buscam por conhecimento cientifico.

Desta maneira, faz-se necessário que se esclareça o real significado das Feiras de Ciências para que os professores, alunos e comunidade em geral conheçam de fato seu objetivo. Corroborando com este pensamento Moraes (1989, p. 20) destaca que:

A Feira de Ciências é um empreendimento técnico-científico-cultural que se destina a estabelecer o inter-relacionamento entre a escola e a comunidade. Oportuniza aos alunos demonstrarem, por meio de projetos planejados e executados por eles, a sua criatividade, o seu raciocínio lógico, a sua capacidade de pesquisa e seus conhecimentos científicos.

Nesta perspectiva, entende-se que as Feiras de Ciências são espaços vivos de demonstrações, pesquisas, experiências e principalmente obtenção de conhecimento, levando os envolvidos a adquirir habilidades de pesquisa cientifica, além de proporcionar a autonomia aos estudantes.

Por sua vez, na segunda questão buscou identificar como ocorre o envolvimento dos alunos na realização do projeto e todos os professores participantes da pesquisa afirmaram que a partir do tema "Ciência para a Redução das Desigualdades", disponibilizado pela SNCT, foram realizados estudos, debates, discussões e pesquisas realizadas pelos alunos com orientação e/ou mediação do professor e, assim, dentro das possibilidades surgiram os subtemas que deram origem aos projetos que foram desenvolvidos com participação dos alunos envolvidos durante o processo.

Em relação a esse processo, Oaigen (2013, p. 87) destaca que:

O aluno precisa ser motivado a avançar na autonomia da expressão, a tomar a iniciativa, a construir espaços próprios, a ser participativo e atuante. $\mathrm{O}$ alunoobjeto é aquele que só escuta e reproduz na prova. O aluno-sujeito é aquele que trabalha com o professor, contribui para construir conhecimento, buscar inovar a prática e participar ativamente em tudo.

Isso vai ao encontro com que os professores destacaram quanto ao envolvimento dos alunos no processo de elaboração do projeto. Os dez professores responderam de forma similar ao professor P4, o qual afirmou "o envolvimento se deu através do tema da Feira de Ciências, onde foi discutido com os alunos, posteriormente escolhido o tema 
e produzido o material para feira". O professor P5 acrescenta que "o envolvimento da turma trouxe responsabilidade, orgulho e entusiasmo para pesquisa".

$\mathrm{Na}$ terceira questão buscou-se compreender o que os professores entendem sobre divulgação científica. Dos 10 professores, oito responderam a esta questão. Entre os respondentes todos fizeram referência ao fato da DC está voltada para a divulgação dos resultados de algum trabalho desenvolvido. Para o professor P3, a DC pode ser entendida como uma "exposição de trabalhos científicos tanto em feiras, publicações, jornais, etc.,", sendo então uma maneira de permitir que um público em geral tenha acesso a informações de cunho científico. Para o professor P9 a relevância está em “divulgar projetos científicos benéficos para mudanças sociais". De fato, divulgar um determinado conceito científico, visa fazer uma aproximação entre os conceitos científicos e a comunidade, buscando contribuir para a melhora da sociedade em algum aspecto estudado.

Para Bueno (2010, p. 5) a divulgação científica "contribui com a inclusão do debate sobre temas especializados e de impacto na vida do indivíduo, buscando permitir que pessoas leigas assimilem novas descobertas e o progresso científico, compreendendo o mundo em que vivem".

A quarta questão buscou saber se as Feiras de Ciências contribuem para a DC em Roraima na concepção dos professores, e todos eles responderam que sim. Porém, apenas dois professores justificaram a sua resposta. P1 respondeu "Esperamos algo melhor. Senti falta das pessoas ligadas à educação e comunidade em geral”. P10 afirmou "Sim, pois muitas pessoas ficam cientes dos projetos". Estando claro na ausência de justificativas por parte de oito professores, que de fato existem dificuldades em reconhecer na Feira de Ciências um espaço para divulgação, popularização e propagação da Ciência. Sendo relevante criar maneiras para socializar com os professores aspectos referentes à DC, podendo ser por meio de uma cartilha digital com acesso fácil aos professores das escolas.

Assim, torna-se oportuno expor o objetivo da divulgação científica. Para França (2015, p.28) o objetivo da DC é “democratizar o acesso ao conhecimento científico e estabelecer condições para a alfabetização científica. Visa à inclusão dos cidadãos no debate sobre temas especializados e que podem impactar sua vida e seu trabalho".

Por fim, na última questão, perguntou-se sobre o objetivo da Feira de Ciências, e os professores apresentaram respostas que se complementaram. Para P1 o objetivo está 
em "descobrir novos projetos para o bem estar das pessoas e interação das escolas". De fato busca-se com a feira potencializar o pensamento social e coletivo. Já para os professores P6 e P8 o intuito da execução da feira é "promover a pesquisa científica". Sendo que por meio da pesquisa científica o aluno pode aguçar seu pensamento e sua prática científica. Por sua vez, o professor P10 acredita que o objetivo da feira seja "proporcionar a sociedade outras formas de conhecimento". Percebe-se nesta resposta a ligação entre as Feiras de Ciências e a DC. Esse professor está ciente da contribuição da feira para a popularização da ciência. Nesta direção, Machado (2014, p.4) ressalta que "a realização da feira e outros eventos de ciência apontam mudanças benéficas nos alunos e professores que se evidenciam durante e a partir dos processos de investigação provocados por estas feiras".

\section{CONCLUSÕES}

Verificou-se que as Feiras de Ciências são espaços que colaboram grandemente para a aprendizagem e desenvolvimento intelectual dos estudantes, bem como, para a divulgação e popularização da Ciência no Estado de Roraima. Sendo oportuno que os professores como orientadores tenham o entendimento sobre o papel das Feiras de Ciências no desenvolvimento dos estudantes, valorizando o evento e possibilitando que os alunos participem ativamente, motivando-os a crítica, a reflexão e resolução de problemas, enquanto divulgam a Ciência.

Neste sentido, percebeu-se que o professor tem um papel preponderante como agente motivador e instigador, que propicia que seu aluno semeie sua semente do conhecimento possibilitando que desenvolva habilidades enquanto executa suas atividades do projeto da Feira de Ciências.

\section{REFERÊNCIAS}

BARROS, H. L. de. Um novo papel da divulgação da ciência: rumo a um contrato tecnológico. In Educação Científica e desenvolvimento: o que pensam os cientistas. Brasília: UNESCO, Instituto Sangari, 2005.

BORBA, E. A importância do trabalho com Feiras e Clubes de Ciências. Repensando o Ensino de Ciências. Caderno de Ação Cultural Educativa. Vol. 03, Coleção Desenvolvimento Curricular. Diretoria de Desenvolvimento Curricular. Secretaria de Estado da Educação de Minas Gerais. Belo Horizonte, 1996, 57p. 
BRASIL. Ministério da Educação. Secretaria de Educação Básica. Programa Nacional de Apoio às Feiras de Ciências da Educação Básica - FENACEB. Brasília, 2006.

BUENO, W. C. B. Comunicação científica e divulgação científica: aproximações e rupturas conceituais. Inf. Inf., Londrina, v. 15, n. esp, p. 1 - 12, 2010.

BUENO, W.; GIACHETI, L. de J. M. Jose Reis: a ciência que fala. São Paulo: Annablume; Fapesp, 2010.

CALDAS, G. Políticas públicas de CT\&I na agenda social? In Com Ciência Ambiental. Campinas: pg 94 a 97, 2010.

DUARTE, A. Roquette Pinto e a Rádio Sociedade do Rio de Janeiro - Coletânea de documentos. 2008. Dissertação (Mestrado em História, Política e Bens Culturais) Fundação Getúlio Vargas. Disponível em: http://www.fiocruz.br/brasiliana/cgi/cgilua.exe/sys/start.htm?infoid=822\&sid=27.

Acesso em 10 de Agosto de 2019.

FRANÇA, A. de A. Divulgação Científica no Brasil: espaços de interatividade na Web. Dissertação de mestrado em Ciência, Tecnologia e Sociedade da Universidade Federal de São Carlos-UFSCar, São Carlos, 2015. Disponível em: https://repositorio.ufscar.br/bitstream/handle/ufscar/7131/DissAAF.pdf?sequence=1\&is Allowed=y. Acesso em 26 de Setembro de 2019.

GARROTI, C. P. Semana Nacional de Ciências e Tecnologia no Brasil: Avanços e desafios. Campinas, SP: (s.n.), 2014.

GIORGION, R. Habilidades Matemáticas Presentes em Alunos do Ensino Médio Participantes em Feira de Ciências. Dissertação de Mestrado na Pontifícia Universidade Católica de São Paulo-PUC/SP. São Paulo: 2010.

MACHADO, S. A Feira de Ciências como ferramenta educacional para formação de futuros pesquisadores. Congreso Iberoamericano de Ciencia, Tecnología, Innovación y Educación. ISBN: 978-84-7666-210-6 - Artículo 1204. Buenos Aires, Argentina. 2014.

MASSARANI, L. Divulgadora científica e diretora do Museu da Vida/Casa de Oswaldo Cruz/Fiocruz. Ildeu de Castro Moreira é físico, historiador da ciência e professor do Instituto de Física da UFRJ. São organizadores, junto com Fátima Brito, de Ciência e público: caminhos da divulgação científica no Brasil. (Casa da Ciência/UFRJ, 2002) e, com Jon Turney, de Terra incógnita - A interface entre ciência e público. (Vieira \& Lent, 2005). Disponível em: http://ppghcs.coc.fiocruz.br/index.php/br/docentes/103-corpo-docente/165-luisamedeiros-massarani. Acesso em 02 de Setembro de 2019.

MINISTÉRIO DA CIÊNCIA, TECNOLOGIA, INOVAÇÕES E COMUNICAÇÕES (MCTIC), $2017 . \quad$ Disponível em: http://www.mctic.gov.br/mctic/opencms/salaImprensa/noticias/arquivos/2017/12/MCTI 
C_apresenta_mapa_da_Semana_Nacional_de_Ciencia_e_Tecnologia_com_recorde_de_ municipios_participantes.html. Acesso em 20 Agosto de 2019.

NETTO, L. F. Feira de Ciências 2010. Divulgador científico, Webmaster e autor do site Feira de Ciências, Coordenador do Parque da Ciência de Barretos. Disponível em: http://www.feiradeciencias.com.br/. Acesso 20 Agosto de 2019.

OAIGEN. E. R. Revista Destaques Acadêmicos / Fundação Vale do Taquari de Ensino Superior e Desenvolvimento Social - vol. 1, n. 1 (2009). - Lajeado, RS: Univates. Edição especial, 2013. Disponível em: http://www.univates.br/revistas/index.php/destaques/article/viewFile/357/351. Acesso em 26 de Setembro de 2019.

ORMASTRONI, M. J. S. Manual de Feira de Ciências. Brasília: CNPq, AED, 1990.

SILVA, N. de O.; ALMEIDA, C. G. de A.; LIMA, D. R. S.; Feira de Ciências: Uma estratégia para promover a interdisciplinaridade. Revista Destaques Acadêmicos, Lajeado, v. 10, n. 3, 2018. ISSN 2176-3070 DOI: http://dx.doi.org/10.22410/issn.21763070.v10i3a2018.1727. Disponível em: http://www.univates.br/revistas/index.php/destaques/article/viewFile/1727/1390. Acesso em: 26 de Setembro de 2019.

SOUSA, M. do S. M. de. As feiras de ciências em Roraima no período de 1986 a 2008: contribuição para a iniciação à educação científica. Dissertação de Mestrado na Universidade Estadual de Roraima - UERR. Boa Vista: 2015.

VALERIO, P. M. C. M. Periódicos científicos eletrônicos e novas perspectivas de comunicação e divulgação para a ciência. Tese (Doutorado em Ciência da Informação). Rio de Janeiro: CNPq/IBICIT-ECO/UFRJ, 2005. 